\title{
Desempenho Produtivo e Padrões de Localização Industrial no Norte do Brasil
}

\author{
André Luiz Ferreira e Silva ${ }^{1}$ (D) | Marcelo Bentes Diniz ${ }^{2}$ \\ ${ }^{1}$ Professor Adjunto do Instituto de Ciências Sociais Aplicadas da Universidade Federal do Pará (ICSA/UFPA), \\ Belém, PA, Brasil. E-mail: alufpa@gmail.com \\ 2 Professor Associado do Programa de Pós-Graduação em Economia da Universidade Federal do Pará (PPGE/UFPA), \\ Belém, PA, Brasil. E-mail: mbdiniz2007@hotmail.com
}

\begin{abstract}
RESUMO
Em meio às transformações regressivas ocorridas na indústria brasileira, o artigo analisa como esse processo tem afetado o desempenho produtivo e a configuração espacial da estrutura industrial no Norte do Brasil. Para tanto, coeficientes de aglomeração e coaglomeração usualmente empregados na literatura sobre geografia econômica e localização industrial foram examinados no período 2007-2017. Em linhas gerais, atividades geograficamente mais concentradas, obtiveram melhores performances em termos de produtividade do trabalho. Mas, a forte heterogeneidade estrutural compromete a performance mesmo entre setores com padrões tecnológicos semelhantes. Além disso, indústrias de commodities minerais que já exerciam forte influência na estrutura produtiva regional estão crescendo rapidamente. Quadro diferente é observado entre os fabricantes de bens de capital e duráveis, cujo crescimento lento condiz com modesta evolução nas conexões intersetoriais locais.
\end{abstract}

\section{PALAVRAS-CHAVE}

Localização industrial, Índice de aglomeração e coaglomeração

\section{Productive Performance and Industrial Agglomeration Patterns in Northern Brazil}

\begin{abstract}
Amid the regressive transformations that occurred in the Brazilian industry, the article analyzes how this process has affected the productive performance and the spatial configuration of the industrial structure in Northern Brazil. For this, agglomeration and coagulation coefficients usually used in the literature on economic geography and industrial location were examined in the period 2007-2017. In general, geographically more concentrated activities, obtained better performances in terms of labor productivity. However, the strong structural heterogeneity compromises performance even among sectors with similar technological standards. In addition, mineral commodity industries, which already had a strong influence on the regional productive structure, are growing rapidly. A different picture is observed among manufacturers of capital and durable goods, whose slow growth is consistent with modest evolution in local intersectoral connections.
\end{abstract}

\section{KEYWORDS}

Industrial location, Agglomeration and coaglomeration index

\section{CLASSIFICAÇÃO JEL}

R11, R12 


\section{Introdução}

A despeito da vertente teórica, estudos recentes têm reforçado que ganhos de produtividade surgem em clusters industriais. As fontes, que a rigor são não excludentes, surgem com a especialização produtiva tipo Marshall-Arrow-Romer, com economias de urbanização tipo Jacobs e com as estratégias competitivas de Porter (Nallari e Griffith, 2013). Os métodos cada vez mais aderentes aos microfundamentos em economias de aglomeração têm demonstrado que o crescimento regional está fundamentalmente relacionado com desempenho de firmas industriais (Henderson, 2003; Andersson e Lööf, 2011; Du e Vanino, 2021), salário diferencial, qualificação do trabalhador e surgimento de novas ocupações (Florida et al., 2012; Groot et al., 2014; Gabe e Abel, 2016).

Evidências também têm sido frequentes em economias emergentes, com clusters heterogêneos. Por exemplo, Fan e Scott (2003), um estudo realizado para o setor industrial entre as províncias chinesas encontrou evidências de efeitos aglomerativos sobre a produtividade, com diferenças significativas em nível setorial. Tveteras e Battese (2006), por sua vez, constataram que o aumento da densidade de produtores tem um efeito positivo sobre o nível de eficiência técnica, na indústria pesqueira (aquicultura) do Salmão na Noruega. Entre 2005 e 2010, Francois e Nguyen (2017) também encontram uma correlação positiva entre produtividade e densidade da firma industrial no Vietnã.

No Brasil, estruturas industriais periféricas, como as localizadas na Região Amazônica, estão sofrendo um processo de reestruturação, mobilizando recursos na direção de produtores de commodities baseados em vantagens naturais (Monteiro Neto e Silva, 2018; Silva e Diniz, 2020). Evidentemente, esse padrão de crescimento não atende às expectativas a longo prazo, seja porque compromete a estabilidade produtiva, aumentando a pressão sobre o uso do solo e os recursos naturais, seja porque agrava o problema da dependência estrutural, restringindo a participação de setores intensivos em tecnologia na formação da renda e emprego.

O desenvolvimento industrial no Norte foi coerente com a ideia de integração produtiva que norteou as políticas de industrialização brasileira revigoradas durante a década de 1970 (Kon, 2017). À época, entendia-se que a modernização do parque industrial deveria ser desconcentrada, distribuindo ganhos produtivos por diferentes regiões do país (Diniz, 1993; Diniz e Crocco, 1996). Nesse contexto, o Polo Industrial de Manaus (PIM) se estabeleceu como importante elo da produção de bens de capital e bens duráveis, fortalecido pela migração de empresas especializadas beneficiadas por políticas de incentivos fiscais, em vigor até os dias atuais.

Mais recentemente, o processo de integração da economia da Região Norte ao restante da economia nacional tem sido conduzido pela Política Nacional de Desenvolvimento Regional - PNDR, que vem sendo implantada em etapas. A primeira desenvolvida entre 2003 (regulamentada em 2007) e 2010; a segunda iniciada em 2011, 
estendendo-se até 2018, com uma atualização mais recente ocorrida em 2019, e que a partir, principalmente, da $2^{\mathrm{a}}$ etapa passou a explorar certos setores e microrregiões específicas (Alves et al., 2014) naquilo que foi denominado de rotas de integração regional, no caso da Região Norte, direcionou-se ao aproveitamento de frutos da Amazônia com especial ênfase na cadeia produtiva do açaí; à piscicultura e aquicultura e a produtos derivados da biodiversidade da floresta (Coelho, 2017).

O investimento estatal em obras de infraestrutura também contribuiu para minimizar o problema do isolamento geográfico, fortalecendo centralidades urbanas (Belém e Manaus, principalmente) e facilitando acesso a novas fontes de recursos naturais (Saboia, 2000; Lemos et al., 2005). Como resultado, grandes projetos de exploração de recursos minerais (Projeto Grande Carajás) e hídricos (Hidroelétrica de Tucuruí) que passaram a operar no início dos anos 1980 expandiram-se rapidamente e atualmente constituem importantes elos da matriz industrial brasileira. Outros setores especializados em produtos básicos e semielaborados (indústria madeireira, papel-celulose, alimentos e bebidas) estabelecidos no Norte também foram beneficiados com as politicas governamentais expansionistas esgotadas em meados da década 1980 (Kon, 2017).

Se, de um lado, a abertura comercial dos anos 1990 fez emergir o problema crônico de atraso tecnológico herdado do elevado protecionismo que marcou a industrialização brasileira, por outro, a estabilidade econômica e o controle cambial contribuíram para a modernização produtiva, alavancando a produtividade de setores dinâmicos, baseados em bens de capital e bens duráveis, que formam a base da estrutura produtiva no PIM (Kon, 2017). Ademais, a expansão do comércio conduzida pela globalização, no final da década de 1990, também induziu o crescimento de setores exportadores de produtos básicos e semielaborados, fortalecendo áreas especializadas no Norte do Brasil (Pacheco, 1999; Saboia, 2000; Lemos et al., 2005).

No início dos anos 2000, o país ingressa em um ciclo de crescimento distributivo, fortemente impulsionado por fatores externos, como a demanda por commodities agrícolas e minerais, e por fatores internos de estímulo à distribuição de renda, como a política de valorização do salário mínimo, a expansão do crédito pessoal e o fortalecimento de programas de transferência de renda (De Negri e Cavalcante, 2014; Souza, 2015). Pelo lado da oferta, a reação da produção industrial e a crescente demanda por energia revelaram a necessidade de ampliar a capacidade instalada do recurso mais barato, a energia elétrica. Assim, um conjunto de investimentos nesse setor passou a ser implementado a partir de 2004, alterando a composição estrutural em regiões com grande potencial, caso do Norte do Brasil.

É nesse cenário de mudança na estrutura produtiva regional que o objeto de estudo é construído, avaliando-se como tais mudanças afetaram a configuração espacial das atividades industriais no Norte do Brasil no período 2007 a 2017. Usando uma abordagem diferente, em que a atividade industrial é agrupada em quatro padrões tecnológicos (Commodities minerais, Indústria tradicional, Energia, químicos e combus- 
tíveis e Bens de capital e bens duráveis), o artigo se insere em um conjunto de estudos que analisaram os impactos regionais da reestruturação produtiva observada na atividade industrial no Brasil em período recente (Sampaio, 2017; Monteiro Neto e Silva, 2018; Silva e Diniz, 2020).

Em termos metodológicos, a correlação entre desempenho produtivo regional, quantificado pela produtividade do trabalho, e concentração geográfica industrial é avaliada de forma exploratória. Para tanto, coeficientes de aglomeração e coaglomeração usualmente empregados na literatura sobre geografia econômica e localização industrial (Krugman, 1991; Ellison e Glaeser, 1997; Ellison et al., 2007) foram estimados e examinados ao longo do período 2007-2017.

Segundo Ellison e Glaeser (1997), esses coeficientes permitem identificar a natureza da localização industrial, se influenciada por vantagens naturais e/ou pelos transbordamentos tecnológicos. Em face dessa propriedade, cabe aplicá-los no Norte, onde a estrutura produtiva heterogênea é continuamente afetada pela tensão entre forças dispersivas orientadas pela produtividade de firmas especializadas em produtos básicos e semielaborados, contrapostas às forças aglomerativas das firmas diferenciadas, fortemente concentradas no PIM.

O problema da heterogeneidade estrutural é examinado, adicionalmente, pela ótica das conexões intersetoriais locais, em que firmas de diferentes padrões tecnológicos tendem a compartilhar o mesmo espaço geográfico, em busca de economias de custo. Neste sentido, evidências sobre a colocalização industrial são obtidas pelos coeficientes de coaglomeração de Ellison e Glaeser (1997), aperfeiçoados por Ellison et al. (2007).

Este artigo foi organizado da seguinte forma: além desta introdução, a seção 2 trata das condicionantes da localização industrial, enfatizando aspectos relevantes da concentração geográfica em economias periféricas. A seção 3 discute os aspectos metodológicos dos indicadores de aglomeração industrial. A análise dos resultados na seção 4 foi dividida em duas partes: análise dos padrões de localização industrial na Região Norte e a evolução dos coeficientes de coaglomeração industrial. Por fim, a seção 5 apresenta as considerações finais.

\section{Condicionantes da localização industrial}

A obra Geography and Trade de Krugman (1991) lançou as bases para a realização de diversos estudos empíricos disseminados em diferentes frentes, a maioria de relevância comprovada acerca das condicionantes da distribuição das atividades econômicas no espaço. Entre elas, destaca-se a identificação de padrões de localização industrial, que passou a merecer atenção especial em termos da formulação de indicadores de aglomeração microfundamentados sob hipóteses da geografia econômica (Ellison e Glaeser, 1997, 1999; Dumais et al., 2002). 
Ao encontro de tentar responder a pergunta: 'Why, then, did so much of U.S. manufacturing stay within this relatively small stretch of territory?', (Krugman, 1991, p.14) argumenta que a explicação está relacionada às vantagens locacionais mutuamente compartilhadas por firmas aglomeradas. Em alguma medida, sua observação converge para a teoria marshalliana da localização, haja vista que firmas manufatureiras passaram a migrar para o Manufacturing Belt em busca de economias de custo e efeitos de escala via demanda (externalidades pecuniárias) proporcionadas pelas aglomerações. Além disso, seguindo o argumento de Marshall (1920), tais vantagens não estariam estritamente condicionadas às forças de mercado, dado que a proximidade geográfica também seria condição necessária à manifestação de externalidades puras relacionadas aos technological spillovers, questão que ganhou destaque nos estudos empíricos posteriores, enquanto importante fonte dos ganhos de produtividade em economias de aglomeração (Glaeser et al., 1992; Henderson et al., 1995; Koo, 2005; Nallari e Griffith, 2013).

Mas, em determinados contextos, aglomerações são explicadas, também, por outros elementos não determinísticos que extrapolam a racionalidade da teoria clássica da localização. Segundo (Krugman, 1991, p.61), a industrialização nos US foi marcada por pequenos acidentes históricos que levaram ao surgimento e declínio de clusters industriais. O autor cita o caso da indústria têxtil, que após a II Guerra migrou do Nordeste (Nova Inglaterra) para regiões mais produtivas no Sul (Dalton, Carolina do Norte e Carolina do Sul). Sobre esse fato, é curioso constatar que a mesma indústria que se moveu dentro do território norte-americano, visando às economias de custo, mais tarde seria surpreendida por efeitos semelhantes imputados pela globalização, que resultaram na migração de firmas tradicionais intensivas em trabalho na direção de mercados emergentes, como China, México e Índia. Temas relacionados às forças de dispersão geográfica, como aumento do nível dos salários industriais nos US, estão no centro das discussões sobre desindustrialização em países desenvolvidos (Krugman e Venables, 1995).

No entanto, a globalização também trouxe benefícios à modernização industrial nos US. Exemplos típicos ocorreram no Vale do Silício na Califórnia e na Rota 128 em Boston, clusters de alto conteúdo tecnológico compostos por firmas ligadas ao setor de microeletrônica, robótica, farmacêutica e biotecnologia. Segundo (Krugman, 1991, p.53), a produtividade nessas áreas se baseia nos knowledge spillovers, transmitidos pelos fluxos de inovações que integravam o setor produtivo (empresas), as instituições de pesquisa e as universidades. Na visão do autor, caberia a estes últimos o fornecimento de mão de obra qualificada, enquanto o setor de pesquisa e desenvolvimento (P\&D) passou a atuar de forma independente da produção industrial, tornando as redes de relacionamentos mais complexas e flexíveis.

Duas questões importantes emergem dessa análise. Em primeiro lugar, a abordagem de Krugman (1991) não descarta da importância dos eventos exógenos, como políticas governamentais, na formação das aglomerações produtivas descentraliza- 
das em economias emergentes. No caso brasileiro, investimento direto na produção, investimentos em transporte, energia e telecomunicações, e incentivos fiscais foram políticas exaustivamente empregadas na tentativa de reverter a polarização produtiva concentrada na Área Metropolitana de São Paulo (AMSP).

Como demonstra a literatura sobre desconcentração produtiva regional no Brasil, os primeiros efeitos espaciais resultantes dessas políticas começaram a ser observados a partir da década de 1970, em polos industriais no interior do estado de São Paulo (Azzoni, 1986). Estudos posteriores demonstraram, entretanto, que a expansão era mais ampla, atingindo um polígono traçada entre o estado de Minas Gerais e o Rio Grande do Sul (Diniz, 1993; Diniz e Crocco, 1996). Mais recentemente, com o aperfeiçoamento das técnicas de análise e estatísticas espaciais, percebeu-se que a expansão produtiva atingiu também polos periféricos no Norte, Nordeste e Centro-Oeste do país (Saboia, 2000; Lemos et al., 2005; Crocco et al., 2006; Saboia, 2013).

Em segundo lugar, a tendência à especialização produtiva determinada pela globalização trouxe grandes desafios aos formuladores de políticas regionais de crescimento redistributivo. Isso ocorreria porque as estruturas produtivas estariam mais condicionadas às especificidades locais, comprometendo o desenho dos arranjos institucionais, importante para os fluxos de conhecimento em economias periféricas (Diniz e Crocco, 2006). No que diz respeito aos fluxos de mercadorias e trabalhadores, haveria ainda o problema da ambiguidade dos custos de transporte, uma vez que a presença de economias de escala nas grandes cidades poderia elevar a concentração produtiva, acentuando a desigualdade econômica regional (Ruiz, 2006).

Contudo, a adoção de políticas verticais e horizontais a partir da abertura comercial contribuiu para a modernização da matriz industrial gerando efeitos positivos sobre a produtividade agregada (Carvalho e Feijó, 2000). Esse fato também está presente nas estatísticas oficiais dos anos 2000, bem como na aceleração da produtividade total dos fatores no início do século XXI (Ellery Jr, 2014; Squeff e De Negri, 2014). Ademais, ainda que muitos autores defendam a tese de desconcentração regional, não há evidência suficiente atestando que os ganhos de produtividade foram capazes de promover mudanças progressivas nos padrões tecnológicos ao longo do território brasileiro, pelo menos de forma isolada.

Sobre essa questão, Saboia (2013) argumenta que a desconcentração diagnosticada no período 1997-2007 beneficiou áreas principalmente no Sul do país, mas também mesorregiões menos desenvolvidas no Centro-Oeste, especialmente; e, embora se observe um certo esvaziamento na AMSP, a sua perda de densidade não representa necessariamente uma perda de centralidade da maior aglomeração industrial do país.

Usando o método shift-share, Galeano e Feijó (2013) alertam para uma certa estagnação que afetaria a produtividade industrial do trabalho das grandes regiões brasileiras (1996-2007). Segundo as autoras, o fraco desempenho produtivo se deu mais em razão da competitividade regional do que das mudanças na estrutura produtiva, 
não implicando alterações relevantes nos padrões tecnológicos regionais.

Analogamente, Sobrinho e Azzoni (2016) identificaram 17 aglomerações industriais relevantes, sendo que $65 \%$ delas estariam concentradas no eixo Sul-Sudeste. Embora as evidências indiquem continuidade do processo de desconcentração industrial, as mudanças (2000-2010) não foram suficientes para alterar o quadro de forte concentração geográfica industrial no Brasil.

Ao investigar mudanças estruturais no desenvolvimento regional brasileiro (19952015), enfatizando a desconcentração espaço-industrial, Monteiro Neto e Silva (2018) constataram que a Região Sudeste foi a que mais perdeu participação no valor da transformação industrial (VTI) nacional (10,7\%), distribuído da seguinte forma: 5\% em direção ao Sul, 3,4\% ao Centro-Oeste, 2,2\% ao Nordeste e 0,3\% ao Norte. Os resultados também revelaram que as indústrias intensivas em recursos naturais, localizadas, principalmente, nas regiões periféricas (Norte, Nordeste e Centro-Oeste), aumentaram significativamente seu peso no VTI total. Porém, tal desempenho tem restringido a diversificação industrial, implicando baixo crescimento da produtividade do trabalho no Brasil.

Por fim, utilizando os índices de Ellison e Glaeser (1997), Silva e Diniz (2020) analisaram mudanças nos padrões de concentração regional da indústria de transformação brasileira no período 2007-2014, com evidências que apontam que esse processo evoluiu rapidamente $(2,7 \%$ a.a.), mas com intensidade variada entre macrorregiões. Assim, as regiões Norte e Nordeste foram mais afetadas pelo processo de desconcentração geográfica industrial, com mudanças mais lentas sendo observadas nas regiões Sul e Sudeste.

\section{Aspectos metodológicos}

\subsection{Indicadores de aglomeração industrial}

O coeficiente Gini locacional proposto por Krugman (1991) serviu de base para a formulação dos indicadores de aglomerações industriais ${ }^{1}$, entre os quais destaca-se o índice Ellison e Glaeser (1997). Esse índice tornou-se popular entre os estudos empíricos, por permitir avaliar se forças que orientam a concentração produtiva são explicadas por vantagens naturais (natural advantages) e/ou transbordamentos tecnológicos (technological spillovers).

Sob um pressuposto básico em economia regional - a concentração industrial não é neutra à concentração geográfica -, os autores combinaram propriedades do índice Hirschman-Herfindahl com o coeficiente Gini locacional de Krugman (1991) e, como resultado, propuseram um mecanismo de correção para identificar o grau de localização em diferentes tamanhos de plantas. Pode-se dizer que essa foi a forma engenhosa

\footnotetext{
${ }^{1}$ Uma revisão abrangente sobre o tema é encontrada em Nakamura e Paul (2009) ou (Combes et al., 2008, cap.10).
} 
encontrada por Ellison e Glaeser (1997) para exercer maior controle sobre os efeitos da heterogeneidade espacial.

Para modelar o problema, os autores consideram que a taxa de lucro da firma depende do valor esperado em dada localidade, dos technological spillovers e de efeitos aleatórios. Então, a firma $k$ escolhe sua localização visando maximizar a seguinte função lucro:

$$
\log \pi_{k i}=\log \bar{\pi}_{i}+g_{i}\left(v_{1}, \ldots, v_{k-1}\right)+\epsilon_{k i} .
$$

em que $\bar{\pi}_{i}$ reflete a expectativa de lucro industrial na área $i, g_{i}(\cdot)$ é uma função para os technological spillovers específicos às indústrias e $\epsilon_{k i}$ é o componente aleatório representado por erros idiossincráticos inerentes à escolha locacional.

O modelo teórico considera que a presença de vantagens naturais (características do clima, acesso a recursos naturais, fontes de energia, entre outras) pode induzir um processo de concentração produtiva local. Por exemplo, a abundância de recursos minerais pode determinar a aglomeração de firmas em dada localidade, com reflexos na expectativa de lucro, definida como um parâmetro da distribuição espacial: $E\left(\bar{\pi}_{i}\right)=$ $x_{i}$. A variância, $\operatorname{var}\left(\bar{\pi}_{i}\right)=\left[\gamma^{n a} /\left(1-\gamma^{n a}\right)\right] x_{i}$, por sua vez, reflete a sensibilidade do lucro em relação às características locais, tal que $\gamma^{n a}$ é um parâmetro das vantagens naturais. Em contrapartida, a concentração produtiva também poderia ser reforçada por externalidades tecnológicas marshallianas, representadas pelo parâmetro $\gamma^{s}$.

Com isso, a localização industrial poderia ser decomposta entre efeitos das natural advantages, pelos technological spillovers ou por combinações das duas forças.

$$
\gamma=\gamma^{n a}+\gamma^{s}-\gamma^{n a} \gamma^{s}
$$

Mudanças espaciais são tratadas inserindo uma variável binomial $u_{k i}$ com distribuição de Bernoulli no índice de concentração geográfica, $G_{i}=\sum_{i}\left(s_{i}-x_{i}\right)^{2}$, proposto por Krugman (1991). Esse procedimento tornou a participação no emprego industrial, $s_{i}=\sum_{k} z_{k} \cdot u_{k i}$, uma variável endógena, à medida que a localização de plantas semelhantes $k$, na área $i$, é identificada através de inferência estatística.

Então, tomando a expectância matemática do índice de concentração bruta, demonstrase a existência de uma relação entre forças de concentração vertical representadas pelo índice Herfindahl, $H_{i}=\sum_{k} z_{k}^{2}$, e pelas forças de dispersão capturadas pelo índice $G_{i}$ de concentração geográfica.

$$
E\left(G_{i}\right)=\left(1-\sum_{i} x_{i}^{2}\right)\left[\gamma+(1-\gamma) H_{i}\right]
$$

Substituindo (3) em (2), um estimador para o excedente de aglomeração pode ser 
obtido através do emprego observado em nível da planta industrial.

$$
\hat{\gamma}_{i} \equiv \frac{E\left(G_{i}\right) /\left(1-\sum_{i} x_{i}^{2}\right)-H_{i}}{\left(1-H_{i}\right)}=\frac{\sum_{i}\left(s_{i}-x_{i}\right)^{2} /\left(1-\sum_{i} x_{i}^{2}\right)-\sum_{k} z_{k}^{2}}{\left(1-\sum_{k} z_{k}^{2}\right)}
$$

em que $s_{i}$ é a participação no emprego industrial na área $i, x_{i}$ é a participação local no emprego total e $z_{k}$ é a participação da planta $k$ no emprego industrial.

Além de (4), Ellison e Glaeser (1997) consideraram ainda a possibilidade de plantas diferentes ocuparem a mesma área em função dos technological spillovers. Por exemplo, a eficiência dos serviços de infraestrutura urbanos pode potencializar o desempenho de indústrias diferentes, promovendo a diversificação industrial. Assim, considerando que a proximidade entre duas plantas $k$ e $l$ melhora a performance conjunta, $\operatorname{corr}\left(u_{k i}, u_{l i}\right)=\gamma^{c}$, um estimador consistente para o coeficiente coaglomeração pode ser obtido por:

$$
\hat{\gamma}_{i \in r}^{c} \equiv \frac{G_{i \in r}^{E G}-\sum_{i \in r} w_{i \in r}^{2} H_{i \in r}-\sum_{i \in r} \hat{\gamma}_{i \in r} w_{i \in r}^{2}\left(1-H_{i \in r}\right)}{1-\sum_{i \in r} w_{i \in r}^{2}}
$$

em que $H_{i \in r}$ é um índice Hirchman-Herfindahl com a concentração do emprego das plantas $i$ agrupadas em $r, w_{i \in r}$ é a participação da indústria $i$ no emprego em $r$, e $G_{i \in r}^{E G}=\left[\sum\left(s_{i \in r}-x_{i \in r}\right)^{2} /\left(1-\sum_{i \in r} x_{i \in r}^{2}\right)\right]$ é a concentração geográfica mensurada no nível do grupo $r$. Segundo Ellison et al. (2007), os coeficientes (5) são estimados por pares industriais, tal que a evolução é avaliada pela seguinte taxa geométrica de crescimento:

$$
g=k^{-1} \cdot \log \left(\frac{\gamma_{1}^{c}}{\gamma_{0}^{c}}\right)
$$

em que $k$ é uma constante, $\gamma_{0}^{c}$ e $\gamma_{1}^{c}$ são os níveis de coaglomeração inicial e final, respectivamente.

Como dito, uma vantagem em (4) é realizar comparações, mesmo entre indústrias de padrões tecnológicos distintos. Por exemplo, se $i$ for uma indústria muito competitiva, formada por muitas firmas de pequeno porte, a concentração medida por $H_{i}$ terá pouco impacto em $\gamma$, logo sua determinação dependerá exclusivamente de $G_{i}$. Mas, à medida que a competição vai se tornando imperfeita, $H_{i}$ aumenta relativamente, podendo surgir um padrão de monopólio, $\operatorname{com} \gamma<0$.

Um resultado não trivial do modelo é considerar que plantas escolhem sua localização através de critérios arbitrários ou aleatórios, restringindo (3) a $E\left(G_{i}\right)=$ $\left(1-\sum_{i} x_{i}^{2}\right) H_{i}$. De acordo com Farhauer e Kröll (2014), a hipótese de ausência de forças aglomerativas, $H_{0}: \gamma^{n a}=\gamma^{s}=0$, pode ser testada por: 


$$
z_{i}=\frac{G_{i}-\left(1-\sum_{i} x_{i}^{2}\right) H_{i}}{\sqrt{\operatorname{var}\left(G_{i}\right)}}
$$

em que o denominador da estatística teste é composto pelo desvio padrão da concentração bruta:

$$
\operatorname{var}\left(G_{i}\right)=\left\{H_{i}^{2}\left[\sum_{i} x_{i}^{2}-2 \sum_{i} x_{i}^{3}+\left(\sum_{i} x_{i}^{2}\right)^{2}\right]-\sum_{k} z_{k}^{4}\left[\sum_{i} x_{i}^{2}-4 \sum_{i} x_{i}^{3}+3\left(\sum_{i} x_{i}^{2}\right)^{2}\right]\right\}
$$

Para fornecer uma medida de probabilidade $\Phi(z)$ usada no teste de significância, a estatística (7) deve ser comparada à distribuição normal padrão acumulada. Então, para um nível de confiança em 90\%, a hipótese nula não pode ser rejeitada sempre que $1-2[1-\Phi(z)] \leq 0,90$.

Agregando as firmas industriais por microrregião, os índices (4) e (5) foram calculados em duas coberturas setoriais: a primeira envolvendo 26 atividades industriais classificadas em nível das divisões (2 dígitos) da CNAE 2.0 (Classificação Nacional de Atividades Econômicas); e a segunda, com a firma agrupada de acordo com seu padrão tecnológico, discutido com mais detalhes na seção seguinte.

\subsection{Padrões tecnológicos}

Desde a abertura comercial nos anos 1990, cresceu o interesse em propor critérios para categorização de firmas segundo padrão tecnológico. Nesse sentido, um estudo pioneiro foi o de Ferraz et al. (1996), que, sob pressupostos da teoria da competitividade, argumentaram que a indústria brasileira poderia ser agregada em quatro grupos: Commodities, Duráveis e seus fornecedores, Tradicional e Difusores de progresso técnico.

Na mesma linha, argumentando que firmas competem via sistema de preços e por diferenciação de produtos ou processos, sendo a primeira mais promissora para a lucratividade da empresa, De Negri et al. (2005) propuseram que a indústria brasileira fosse tipificada entre: (a) Firmas que inovam e diferenciam produtos, (b) Firmas especializadas em produtos padronizados e (c) Firmas que não diferenciam produto e têm produtividade menor.

Visando analisar a trajetória recente dos indicadores de inovação no Brasil (19982008), bem como buscar explicações para o desempenho relativamente modesto da produtividade brasileira, Cavalcante e De Negri (2011) agregaram 32 setores da indústria de transformação em quatro grupos de acordo com o grau de intensidade tecnológica (alta, média-alta, média-baixa e baixa) proposto pela OCDE.

Para analisar se o crescimento entre as grandes regiões brasileiras foi mais favore- 
cido por mudanças estruturais ou se pela própria competitividade regional, Galeano e Feijó (2013) aplicaram método shift-share na decomposição da produtividade industrial do trabalho (1996-2007), classificando setores 2 dígitos CNAE por grau de intensidade tecnológica. Estratégia semelhante foi adotada por Galeano e Wanderley (2013).

Para examinar modificações no padrão regional das aglomerações industriais no Brasil (2003-2011), usando técnicas de análise multivariada para agrupamento, Saboia et al. (2014) classificaram setores 2 dígitos CNAE em três grupos, definidos de acordo com os critérios de Ferraz et al. (1996), quais sejam: (1) Commodities, (2) Difusoras/Duráveis e (3) Indústrias tradicionais.

Assim, embora exista alguma diferença relacionada ao método de agrupamento ou à identificação das categorias de análise; ulteriormente, os critérios remetem à natureza da estrutura produtiva. Então, considerando que padrões tecnológicos guardam estreita relação com a natureza das economias de aglomeração, propõe-se uma taxonomia aplicada a 26 setores que caracterizam a estrutura produtiva na Região Norte. ${ }^{2}$

(1) Commodities minerais - composto por firmas especializadas na produção homogênea, com baixo valor adicionado e voltadas ao mercado externo. Em geral, a produtividade desse padrão é sustentada por uma empresa de grande porte, fortemente localizada em função de recursos minerais.

(2) Indústria tradicional - composto por segmentos da indústria de transformação que competem no mercado interno, porém dotadas de tecnologia com baixo grau de diferenciação. A produtividade regional é impulsionada por vantagens comparativas relacionadas ao extrativismo vegetal, à agricultura e à pecuária.

(3) Energia, químicos e combustiveis - também composto por firmas especializadas na produção homogênea, porém voltadas ao suprimento do mercado interno. Neste padrão, a produtividade regional é fortemente dependente das fontes de recursos hídricos.

(4) Bens de capital e bens duráveis - são firmas especializadas na produção de bens de capital, importantes para a difusão tecnológica, e fabricantes de bens de consumo duráveis. Integram este padrão os segmentos mais dinâmicos da indústria de transformação, classificados com alta ou média-alta intensidade tecnológica.

A agregação por padrão tecnológico, além de facilitar a análise, permite demonstrar como a concentração geográfica do padrão (4) pode ser fortemente sustentada pelos technological spillovers, ao passo que outros padrões, como (1) e (3), dependeriam de

\footnotetext{
${ }^{2}$ Compreendem divisões (2 dígitos CNAE 2.0) da Indústria extrativa, Indústria de transformação e Geração e transmissão de energia elétrica, todas relevantes na composição da estrutura produtiva regional, como mostra a Tabela 1. Por terem baixa ou nenhuma participação no VTI, Extração de carvão mineral, Extração de petróleo e gás natural, Atividades de apoio à extração de minerais e Fabricação de produtos do fumo, foram retirados da amostra.
} 
vantagens naturais (Ellison e Glaeser, 1997). Aqui, a correlação entre desempenho produtivo e concentração geográfica é aferida por meio de um modelo de regressão linear simples, em que o logaritmo da produtividade industrial do trabalho, $\log (p)=$ $\log (V T I / P O)$, é estimado em termos do índice Ellison-Glaeser exposto em (4).

\subsection{Dados}

Para viabilizar a análise, foi necessário recorrer a duas fontes de dados, frequentemente empregadas em estudos regionais: A RAIS (Relação Anual de Informações Sociais) Estabelecimento, atualmente gerenciada pela Secretaria do Trabalho, vinculada ao Ministério da Economia; e a Pesquisa Industrial Anual Empresa (PIA-Empresa), coordenada e divulgada pelo IBGE (Instituto Brasileiro de Geografia e Estatística). Por fornecer o estoque de emprego em nivel da firma industrial, a primeira foi usada no cálculo dos índices de aglomeração e coaglomeração. ${ }^{3}$

A principal vantagem da RAIS Estabelecimento está na identificação de algumas características importantes, como o número de emprego, atividade econômica, tamanho e localização da firma individual. Uma mudança importante que elevou a precisão dos indicadores regionais foi a obrigatoriedade da declaração por CNPJ específico. Esse procedimento eliminou a possibilidade de uma empresa multiunidades, por exemplo, concentrar as informações declaradas em único CNPJ, geralmente o da matriz.

No entanto, existem desvantagens no uso da RAIS. Uma delas é a cobertura das relações contratuais, que não alcança o mercado de trabalho informal, problema que pode ser ainda mais grave em microrregiões isoladas, como algumas encontradas no Norte do Brasil. Uma forma de contornar esse problema consiste na análise evolutiva dos indicadores de concentração ao longo de 2007 a 2017, presumindo-se que se trata de um aspecto singular da heterogeneidade regional, mantido invariante no tempo.

A segunda base forneceu os dados para análise do desempenho de 26 atividades industriais distribuídas no Norte do Brasil, quantificado pela razão direta entre o valor da transformação industrial e pessoal ocupado (VTI/PO). A PIA-Empresa constitui uma importante base de dados sobre as características estruturais da indústria brasileira. Em termos regionais, ela cobre os estados da federação, com decomposição setorial que pode chegar ao nível das divisões (2 dígitos) da CNAE 2.0. Ademais, agregações superiores da indústria extrativa e de transformação (seções B e C) são compativeis com dados do Sistema de Contas Nacionais (SCN), inclusive em sua abordagem regionalizada do Sistema de Contas Regionais (SCR), que forneceu os índices de preços setoriais empregados como deflatores implícitos do VTI. Esse procedimento permitiu avaliar a evolução da produtividade industrial do trabalho, comparativa ao ano-base 2007.

\footnotetext{
${ }^{3}$ Devido à complexidade do cálculo, rotinas computacionais foram desenvolvidas em $\mathrm{R}$, visando tabular e organizar os microdados, ao passo que índices (4) e (5) foram estimados com auxílio do pacote REAT (Regional Economic Analysis Toolbox).
} 


\section{Análise dos resultados}

Inicia-se explorando as condicionantes da concentração geográfica industrial, segundo padrão tecnológico. Nessa etapa, a correlação entre os indicadores de aglomeração e a taxa de variação da produtividade do trabalho revelam um aspecto interessante do crescimento desigual. A análise é completada com a evolução das coaglomerações industriais.

\subsection{Padrões de localização industrial no Norte}

Uma característica marcante no Norte é a forte heterogeneidade espacial, representada por um espaço excessivamente fragmentado, que concentra em áreas específicas atividades especializadas em recursos naturais, bem como indústrias diferenciadas baseadas em economias de urbanização. A Figura 1 expõe essa dicotomia, mostrando que, embora pequenas aglomerações ocupem espaços periféricos, grande massa produtiva permanece concentrada no Polo Industrial de Manaus (PIM). ${ }^{4}$

A produtividade no PIM é sustentada pela fabricação de eletroeletrônicos, máquinas e equipamentos, componentes de informática e comunicação, veículos automotores, atividades motrizes do crescimento local, geradoras de externalidades positivas sobre outros setores da estrutura produtiva regional. Para ilustrar o poder de localização dessas atividades, não por acaso, 65\% do VTI dos Fabricantes de produtos alimentícios e 93\% do VTI dos Fabricantes de bebidas, foram gerados no PIM em 2007.

Com relação à concentração de Bens de capital e bens duráveis, todos os índices estimados podem ser considerados estatisticamente significantes a $5 \%$ de probabilidade de erro (Tabela 2 e Figura 2). Examinando sua evolução, não há evidência suficiente que ateste um processo de dispersão geográfica absoluto ocorrendo nesse padrão. O que se observa é uma lenta recuperação iniciada em 2012, porém incapaz de alcançar o nível de atividade referencial de 2007.

Como dito anteriormente, os investimentos em infraestrutura facilitaram o acesso a novas fontes de recursos naturais, reduzindo o custo de implantação de grandes projetos voltados à exploração de recursos minerais e hídricos. No primeiro caso, o potencial é tão significativo que o setor minero-metalúrgico tornou-se o principal vetor de crescimento em áreas da Amazônia Ocidental, em especial no Pará, onde estão as maiores reservas minerais do território nacional. Em consequência, o estado tornouse o segundo maior produtor de commodities minerais do Brasil, respondendo com cerca de $90 \%$ do VTI regional e 13\% da produção nacional. Internamente, o referido padrão aumentou sua participação no VTI regional de 25,15\% para 56,21\%, entre 2007 e 2017 (Tabela 2).

Outra característica de Commodities minerais é a forte instabilidade espacial (Fi-

\footnotetext{
${ }^{4}$ Para exemplificar, $70 \%$ do VTI da indústria de transformação regional foi gerado no âmbito do PIM em 2007 (IBGE, 2014).
} 
Figura 1. Localização industrial no Norte segundo padrão tecnológico (2007).

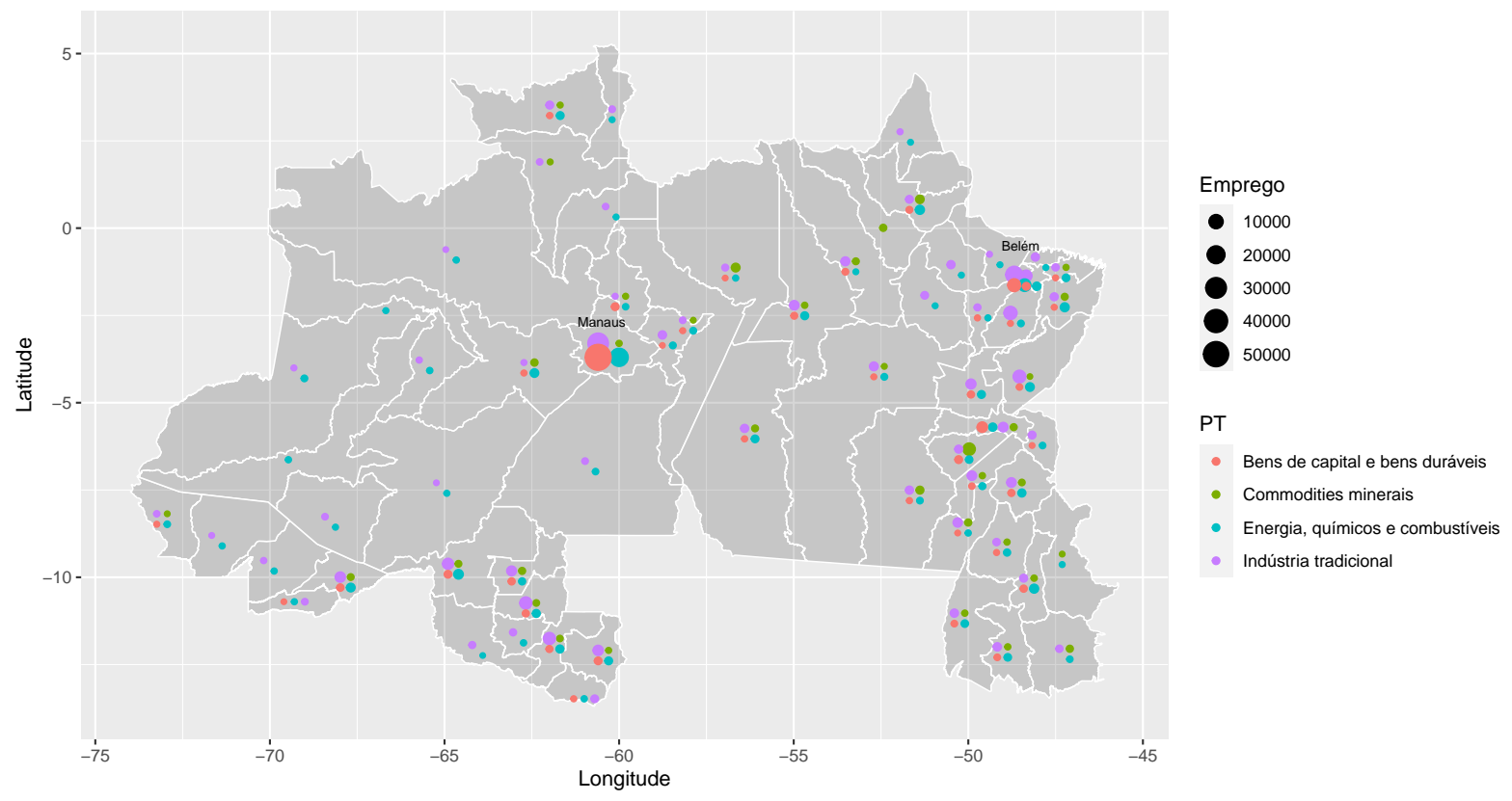

Fonte: RAIS Estabelecimento/Ministério da Economia. Nota: Elaborado pelos autores.

gura 2). Isso decorre de suas características estruturais, a principal delas é a manutenção de uma estrutura intensiva em capital, em que a produção é concentrada em poucas firmas de grande porte, com forte inserção internacional. Para fazer frente à instabilidade dos preços e à pouca flexibilidade em termos de custos fixos, o setor tende a se ajustar frequentemente via demanda por trabalho, com consequências sobre o emprego direto e indireto (Maizels, 1988; Combes e Guillaumont, 2002), o que se reflete no excedente de aglomeração $\gamma$. Então, um choque externo produz um efeito direto sobre a distribuição espacial do emprego, cujo estoque reduz drasticamente nos momentos de incerteza, como ocorrido na crise em 2008 ou no esgotamento do ciclo de commodities em 2014.

Além da expansão da Usina Hidrelétrica de Tucuruí que foi concluída em 2008 e duplicou a sua capacidade geradora de energia (de 4.000 para 8.000 MW) e da construção da Usina Hidrelétrica Teles Pires na fronteira dos estados do Pará (município de Jacareacanga) e Mato Grosso (município de Paranaíta) com capacidade instalada de 1.820 MW, cujas últimas unidades geradoras entraram em operação em agosto de 2016, o maior empreendimento instalado no estado do Pará (e maior do Brasil 100\% nacional) foi a Usina Hidrelétrica de Belo Monte, no Rio Xingu, com capacidade instalada de 11.233 MW, no ano de 2016, entraram em operação três das suas dezoito unidades geradoras. ${ }^{5}$

Mesmo com grande potencial produtivo, os resultados mostram que Energia, quí-

\footnotetext{
${ }^{5}$ Outras usinas de menor porte também passaram a operar a partir de 2006: Peixe Angical (127 MW, 2006), São Salvador (50 MW, 2008) e Estreito (261 MW, 2011), no Tocantins; Santo Antônio (626,3 MW, 2012) e Jirau (1.425 MW, 2014) em Rondônia; Ferreira Gomes (168 MW, 2014) e Santo Antônio do Jari (19,6 MW, 2017), no Amapá (EPE, 2018).
} 
Figura 2. Evolução das aglomerações industriais no Norte segundo padrão tecnológico.

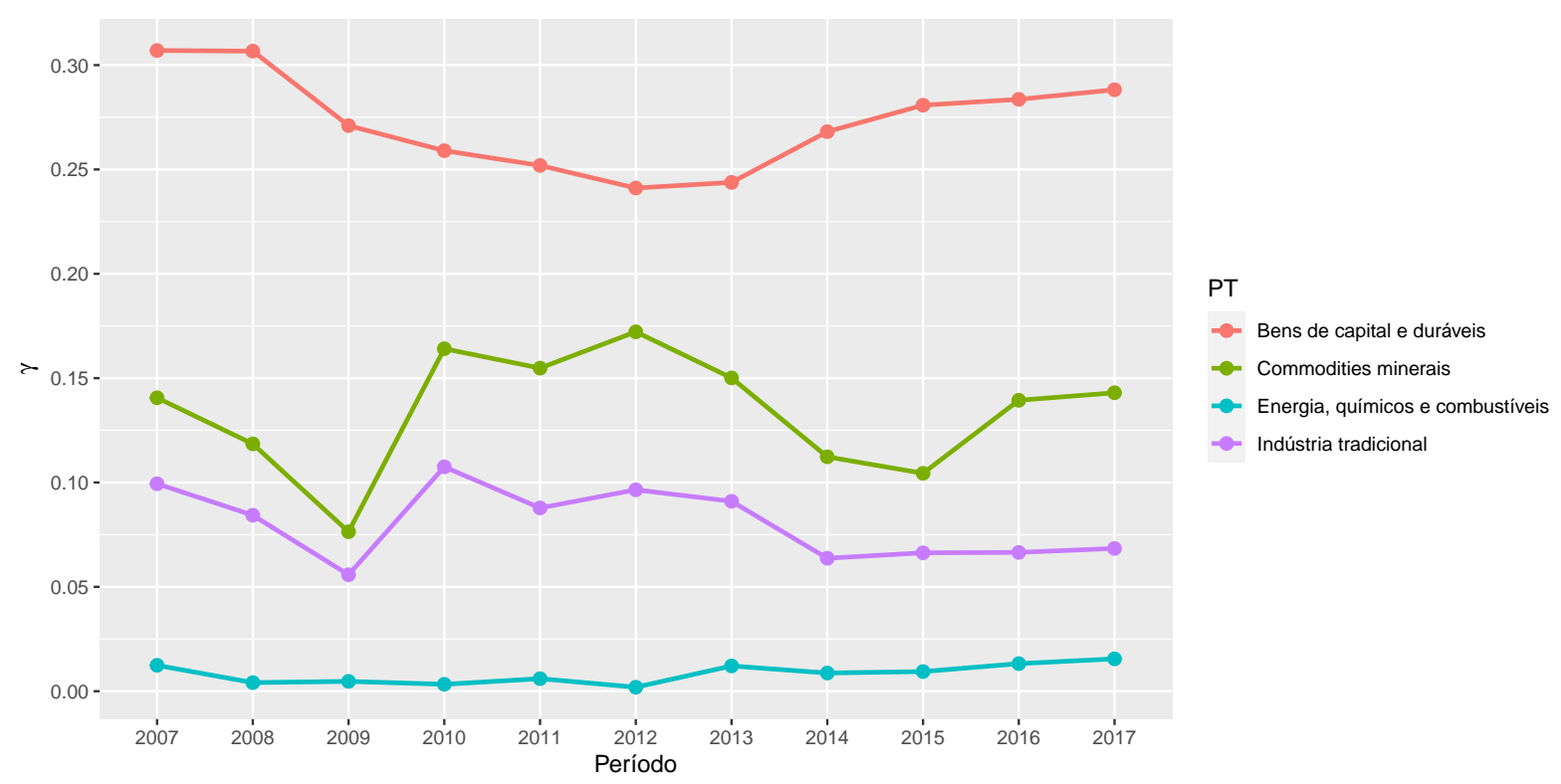

Fonte: Resultado da pesquisa e elaborado pelos autores.

micos e combustiveis não é capaz de produzir externalidade suficiente para promover aglomerações industriais. Embora agregue importantes fontes de matérias-primas, indispensáveis à produção industrial, estimar um $\gamma$ muito próximo a zero (Tabela 2 e Figura 2) indica que o padrão é relativamente bem distribuído no espaço. Além disso, como a Geração e transmissão de energia elétrica é o principal segmento desse padrão, postula-se que o baixo custo de transporte da transmissão estaria neutralizando o efeito proximidade relativo à localização desse padrão.

Enquanto parte da Indústria tradicional se estabelecia no PIM, outros segmentos eram atraídos para regiões periféricas em busca de economias de custo proporcionadas pelo extrativismo florestal, pela agricultura e pela pecuária. No caso dos Fabricantes de produtos de madeira, restrições ambientais têm contribuído para reduzir sua participação no VTI e PO (Tabela 2), com efeitos sobre o coeficiente de aglomeração (Tabela 3), o qual reduziu drasticamente a partir de 2012, principalmente, o que é coincidente com a entrada em vigor do Novo Código Florestal brasileiro e a maior estrutura de governança ambiental imposta na região. Há indícios, também, que tais efeitos afetaram o desempenho de Fabricantes de móveis, Fabricação de celulose $e$ papel e Impressão e reprodução de gravações.

Com relação às atividades sustentadas pela agropecuária, algumas microrregiões se especializaram em padrões agroindustriais. Esse é o caso da agroindústria de polpa de frutas localizada na área metropolitana de Belém e nordeste do Pará; e Áreas Metropolitanas de Manaus (AM) e de Palmas (TO); agroindústria de soja, arroz, milho e mandioca, instaladas nos estados do Pará, Amazonas e Rondônia; agroindústria de 
Tabela 1. Concentração geográfica de firmas industriais segundo padrão tecnológico

\begin{tabular}{lccccc}
\hline \hline Padrão tecnológico & Sig.95\% & Índices & 2007 & 2012 & 2017 \\
\hline (1) Commodities minerais & Sim & $\gamma$ & 0,1406 & 0,1722 & 0,1430 \\
& & $G$ & 0,1373 & 0,1611 & 0,1485 \\
& & $H$ & 0,0334 & 0,0364 & 0,0368 \\
& & $N$ & 754 & 1.114 & 854 \\
\hline (2) Indústria tradicional & Sim & $\gamma$ & 0,0994 & 0,0965 & 0,0684 \\
& & $G$ & 0,0831 & 0,0878 & 0,0608 \\
& & $H$ & 0,0035 & 0,0025 & 0,0033 \\
& & $N$ & 2.788 & 3.044 & 2.605 \\
\hline (3) Energia, químicos e combustiveis & Não & $\gamma$ & 0,0124 & 0,0019 & 0,0155 \\
& & $G$ & 0,0198 & 0,0107 & 0,0214 \\
& & $H$ & 0,0121 & 0,0116 & 0,0097 \\
& & $N$ & 595 & 597 & 591 \\
\hline (4) Bens de capital e bens duráveis & Sim & $\gamma$ & 0,3070 & 0,2411 & 0,2882 \\
& & $G$ & 0,2603 & 0,2022 & 0,2544 \\
& & $H$ & 0,0201 & 0,0168 & 0,0153 \\
\hline \hline
\end{tabular}

Nota. Sig.95\%=Sim, padrão tecnológico com coeficiente $\gamma$ significante a 5\%.

Fonte: Resultado da pesquisa e elaborado pelos autores.

laticínios, fabricantes de couro e frigoríficos, instalados no sul do Pará e, ainda, no estado do Tocantins e, por fim, a indústria de suco de frutas e de doces e geleias, localizadas de forma mais adensada nos estados do Pará, Amazonas e Tocantins. Importa ressaltar que essas cadeias ligadas à fabricação de produtos alimentícios estão se expandido rapidamente, em termos de número de estabelecimentos, como atestam os resultados do Censo Agropecuário de 2017 comparativamente ao de 2006, cuja agroindústria de doces e geleias, sucos de frutas, produtos de panificação e produção de laticínios (queijos e requeijões) cresceu mais 100\% em todos os estados da Região Norte, com efeitos positivos sobre a renda e o emprego.

Isto posto, a Figura 3 mostra a dispersão entre o logaritmo da produtividade do trabalho e o índice de aglomeração industrial, com dados dispostos na Tabela 3. Sem impor maiores restrições ao problema da heterogeneidade estrutural, a correlação entre tais variáveis foi estimada por meio de em modelo pooled OLS convencional.

$$
\log \left(p_{i}\right)=\begin{array}{cc}
4,239 & +1,762 \gamma_{i}, \quad R^{2}=0,051 . \\
(0,163) \quad(0,873) &
\end{array}
$$

Evidencia-se uma correlação positiva significante a 5\% entre a concentração geográfica e a produtividade industrial do trabalho. Assim, mesmo diante da forte heterogeneidade, firmas organizadas em clusters tenderiam a obter melhores resultados do que as periféricas. De fato, os Fabricantes de produtos de informática, eletrônicos 
e ópticos organizados no PIM cresceram (produtividade) em 3,41\% a.a., em média; ao passo que a Extração de minerais metálicos, concentrada no polo industrial de $\mathrm{Pa}-$ rauapebas, cresceu em 8,43\% a.a. (Figura 3 e Tabela 3). Em alguma medida, esse resultado corrobora a hipótese do modelo Ellison e Glaeser (1997), em que atividades específicas são fortemente localizadas em função dos technological spillovers ou natural advantages.

Sobre o problema da heterogeneidade, maior variabilidade é observada no intervalo $\gamma \in[0 ; 0,27]$, correspondente a $80 \%$ das aglomerações industriais (Figura 3). Exceto os Fabricantes de bebidas, para quem um elevado nível de produtividade relaciona-se a um $\gamma$ próximo a zero, grande parte da Indústria tradicional tem baixa produtividade (Tabela 3). Essa discrepância é explicada pela presença de uma grande firma instalada no PIM, cuja escala comprometeria a competitividade dentro do setor.

Indústrias com fraca representatividade na estrutura produtiva, como Fabricação de produtos têxteis, Impressão e reprodução de gravações e Farmoquímicos e farmacêuticos, observam, com frequência, seus coeficientes de aglomeração assumirem valores negativos $(\gamma<0)$. Essa instabilidade espacial é um traço marcante da falta de competitividade setorial, que faz emergir o poder de monopólio.

Figura 3. Correlação entre produtividade do trabalho e aglomerações industriais.

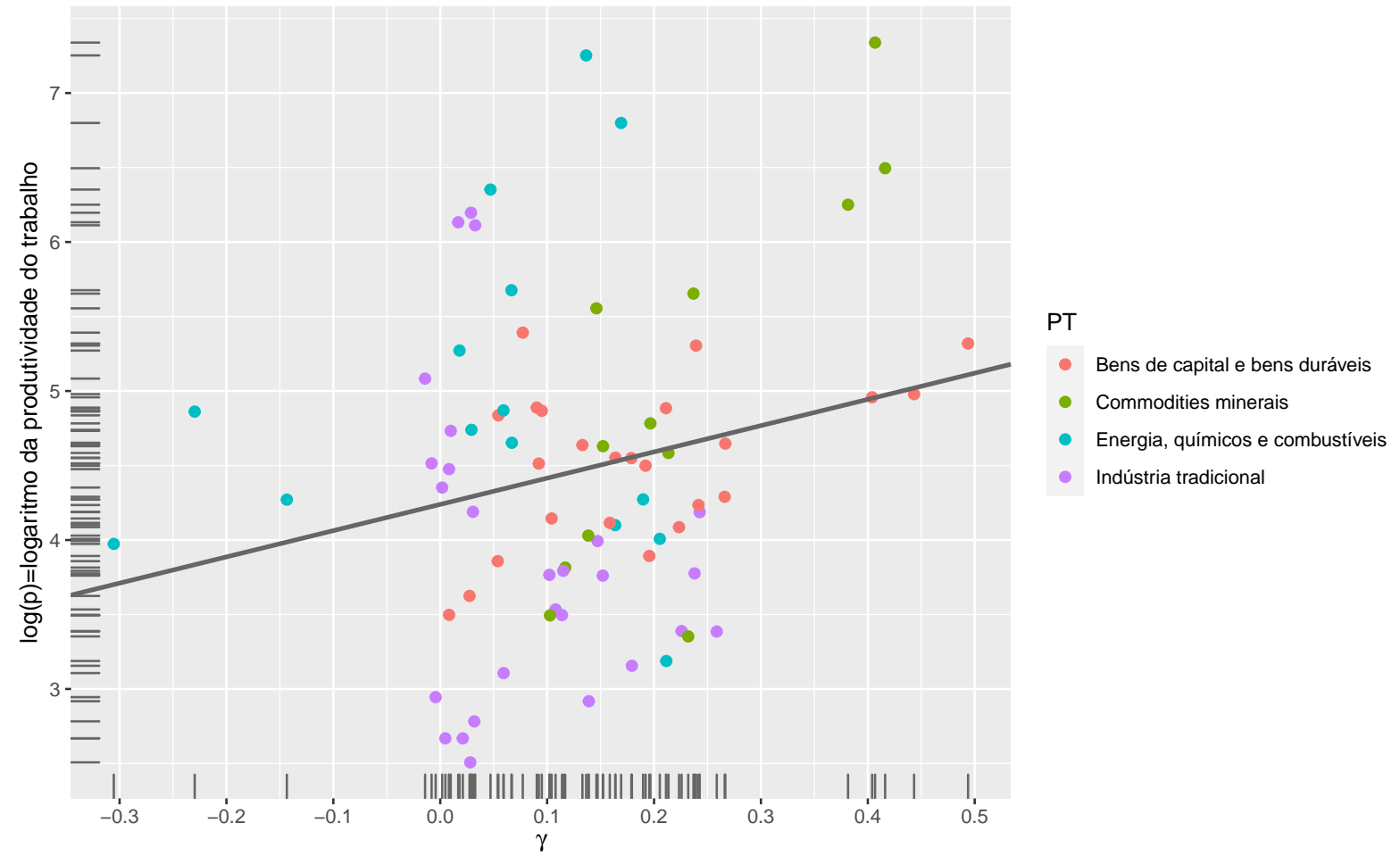

Fonte: Resultado da pesquisa e elaborado pelos autores. 


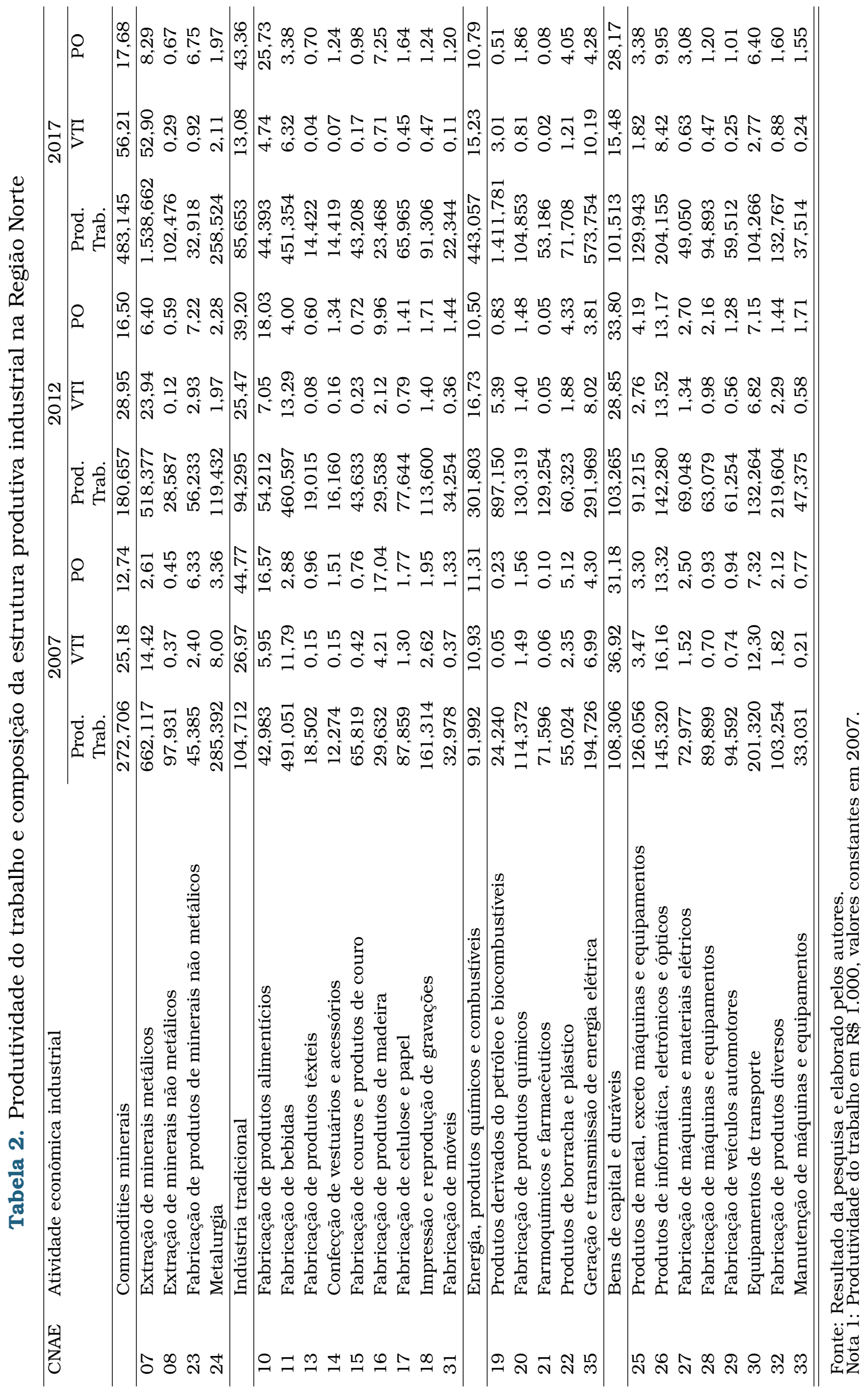




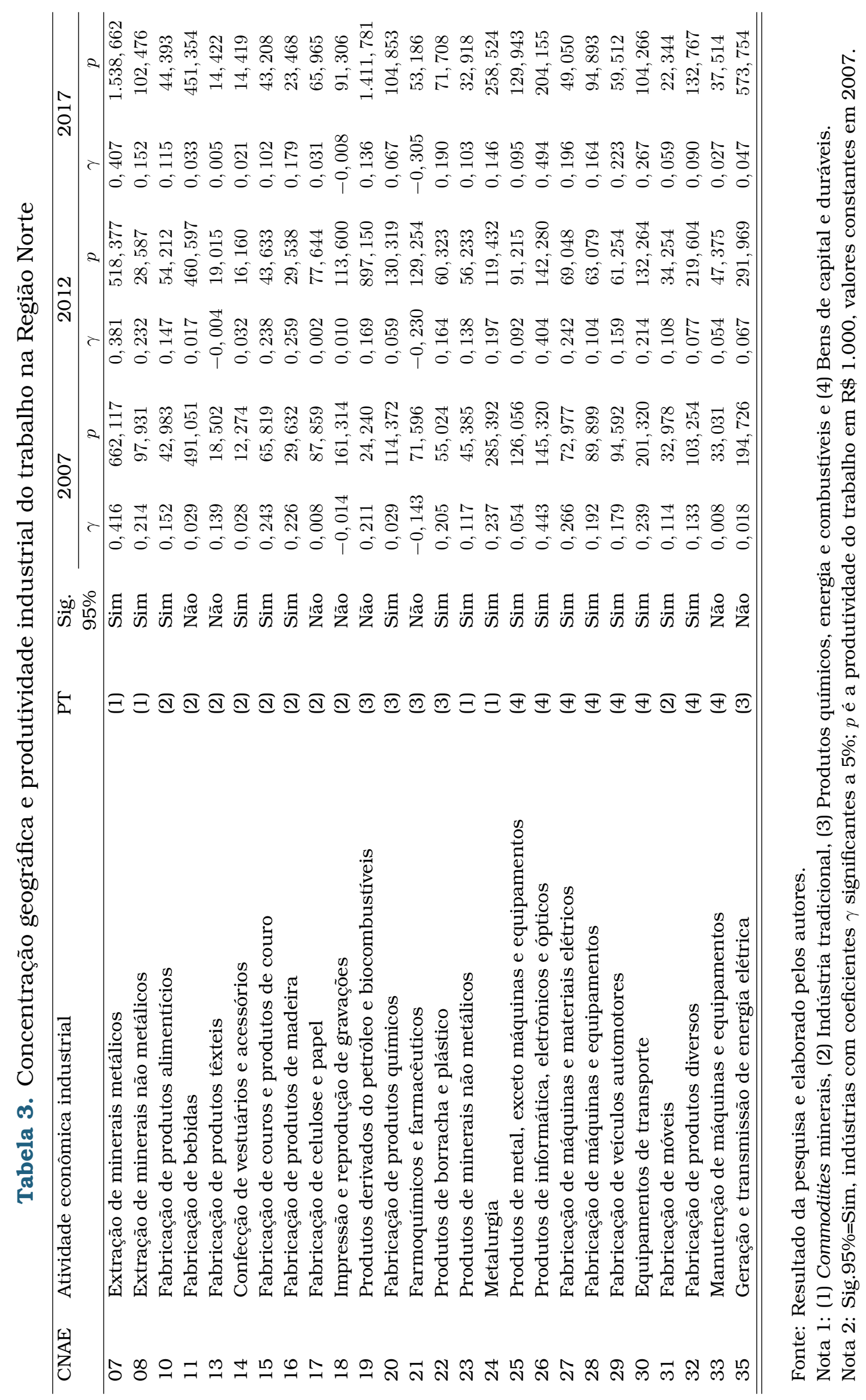




\subsection{Evolução das coaglomerações industriais}

O coeficiente de coaglomeração fornece uma medida da conexão intersetorial local, em que indústrias diferentes compartilham a mesma área, visando a economias de custo. Dado o grande volume de informações, os coeficientes foram organizados na forma de gráficos e matriz de coaglomeração definida a partir dos setores da CNAE a dois dígitos.

O histograma da Figura 4, com coaglomerações agregadas por intervalo de classe, fornece uma alternativa para examinar a concentração produtiva local. De acordo com esse resultado, cerca de $25 \%$ dos arranjos industriais mais localizados (à direita do $3^{\circ}$ quartil) concentraram $52,1 \%$ da densidade produtiva em 2007 , ao passo que os $50 \%$ menos concentrados (à esquerda do $2^{\circ}$ quartil) responderam apenas por $24,6 \%$ da estrutura produtiva regional naquele ano.

Figura 4. Evolução das coaglomerações industriais no Norte.
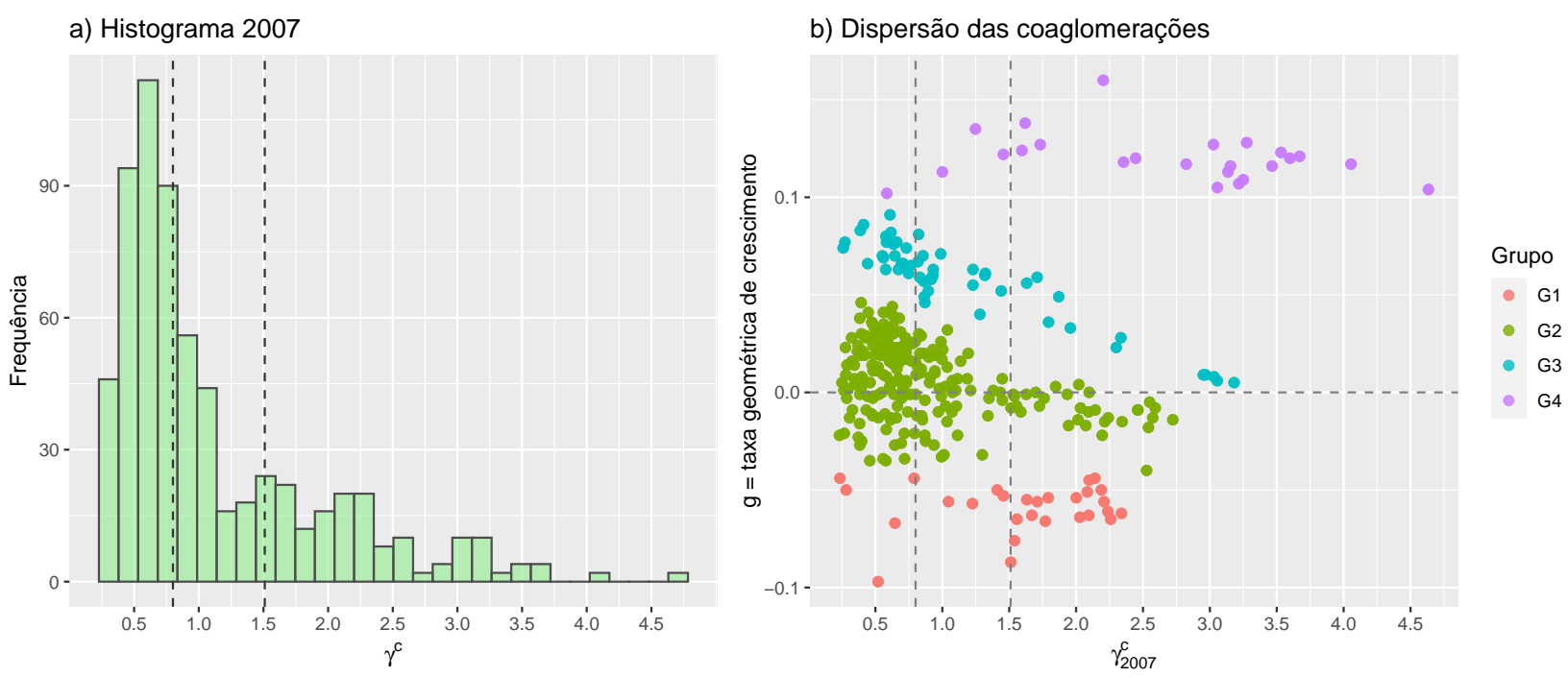

Nota: linhas verticais tracejadas correspondem ao $2^{0}$ e $3^{0}$ quartil.

Fonte: Resultado da pesquisa e elaborado pelos autores.

Os resultados corroboram, ainda, a tendência de transformação (especialização) regressiva, observado, especialmente, na Região Norte de maior dependência na produção de recursos naturais e commodities, o que corrobora os resultados de outros estudos recentes (Monteiro Neto e Silva, 2018; Silva e Diniz, 2020; Monteiro Neto et al., 2021 ). Observa-se, por exemplo, que arranjos pertencentes ao G1 estão enfrentando um processo dispersivo crônico, que independe dos padrões tecnológicos locacionais, que evoluíram a um ritmo acelerado, em 5,91\% ao ano, em média.

De acordo com a Figura 5, essas deseconomias afetaram, principalmente, os $\mathrm{Fa}$ bricantes de produtos de madeira, com efeitos significativos sobre a Impressão e reprodução de gravações. 
A dinâmica das 442 coaglomerações do G2 se diferencia da dinâmica das do G1, à medida que 65\% dos arranjos com fraca e moderada localização incrementaram marginalmente seus níveis iniciais. De certa forma, esse resultado compensou o fraco desempenho de ramos Bens de capital e bens duráveis, responsável pela dispersão observada no G2. De acordo com a Figura 5, o declínio nas taxas de coaglomeração foi puxado pelos Fabricantes de produtos de borracha e plástico, Metal, exceto máquinas e equipamentos, Fabricantes de máquinas e materiais elétricos e Equipamentos de transporte, todos concentrados no PIM.

Observe-se que G1 e G2 são compostos por setores com maior representatividade tecnológicas na Região Norte, porém aparecem reduzindo o grau de interdependência setorial. A exceção fica por conta do setor Produtos de informática, eletrônicos e ópticos, fortemente concentrado no PIM, que reforçou suas taxas de coaglomeração no período analisado.

No G3, todos os 104 arranjos cresceram em relação à condição inicial, com média variando em torno de 5,73\% ao ano. A tendência negativa observada na taxa de coaglomeração mostra apenas que arranjos com forte localização (24) expandiram-se a uma taxa inferior àqueles fracamente localizados (42). Nesse grupo, cabe destacar a participação de três atividades: Extração de minerais metálicos, que influenciou a expansão produtiva em diferentes ramos industriais; Farmoquímicos e farmacêuticos, com traços de monopólio, mas que aparecem integrados a outros segmentos industriais; e Produtos de informática, eletrônicos e ópticos, principal responsável pela sustentação dos niveis de aglomeração em bens de capital e duráveis, mais uma vez em termos espaciais, influenciados pelas empresas situadas no Polo Industrial de Manaus (Figura 5).

Ao contrário do G3, em que a condição inicial é relevante para a expansão produtiva, no G4, os arranjos expandiram a uma taxa constante, em 12,1\% ao ano, em média. Esse desempenho é explicado pela expansão da Fabricação de produtos alimentícios, revelada uniforme no espaço e com capacidade de gerar externalidades sobre diferentes ramos industriais. Como dito anteriormente, esse processo ocorre no PIM e também em microrregiões com potencial para a produção agroindustrial, localizadas em Rondônia, Pará e Tocantins, principalmente.

Em linhas gerais, os resultados obtidos em termos setoriais estão de acordo com outros estudos, que apontam uma maior produtividade do trabalho no setor agropecuário/agroindústria nos estados do Mato Grosso, Tocantins e Rondônia e Indústria de Transformação no estado do Amazonas (Veloso et al., 2021).

Além disso, levando-se em conta outros fatores que podem estar concorrendo para a heterogeneidade dos efeitos aglomerativos sobre a produtividade do trabalho, os resultados estão de acordo com outros apresentados pela literatura empírica. Nessa direção, Rossi et al. (2017) mostram que os spillovers tecnológicos e seus canais de transmissão vão ao encontro do aumento da produtividade e possuem padrões seto- 
Figura 5. Coeficientes de coaglomeração industrial no Norte em 2007.

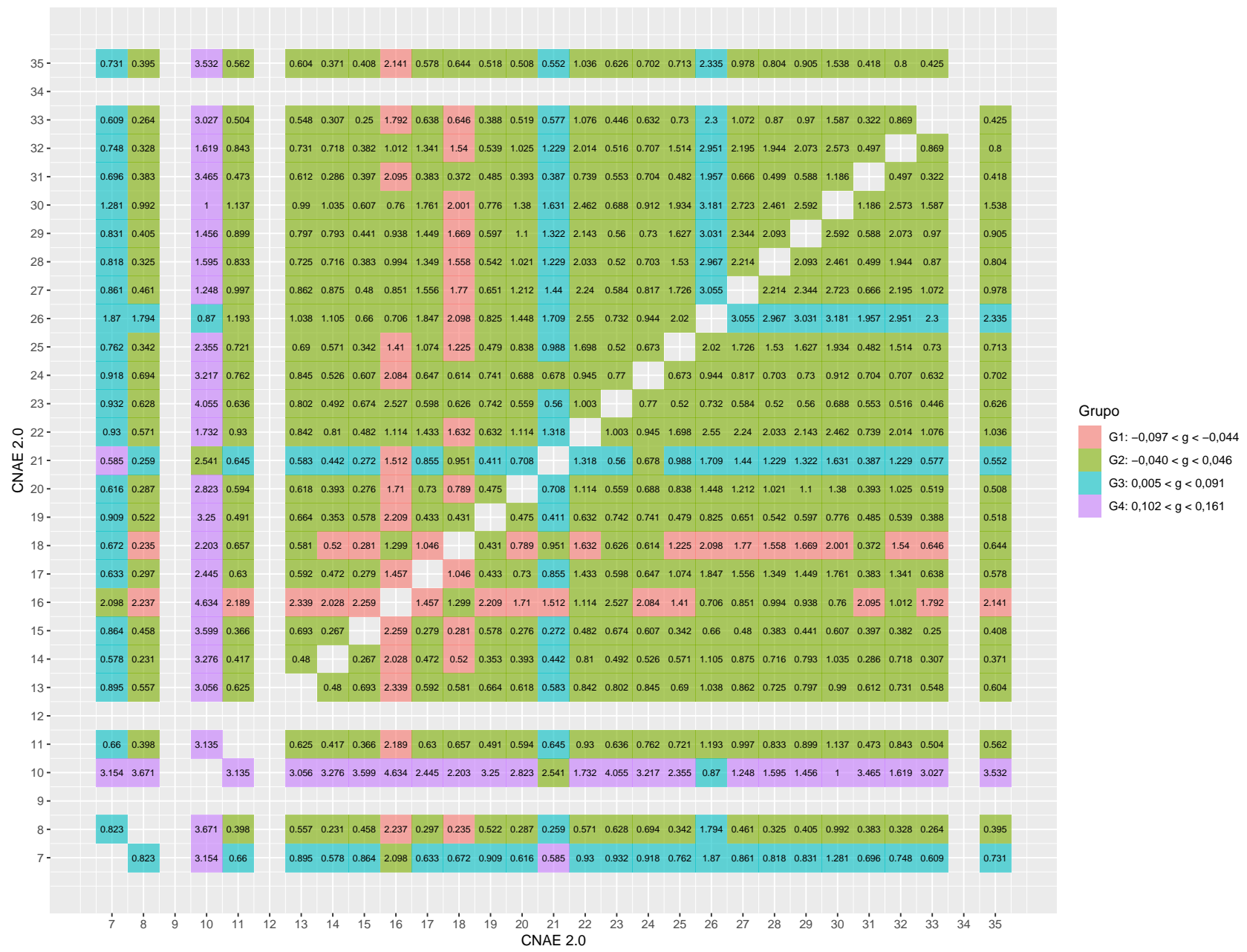

Fonte: Resultado da pesquisa e elaborado pelos autores.

riais e regionais diferenciados em termos da maior ou menor presença de empresas multinacionais no setor. Os resultados encontrados pelos autores acentuam que haveria 'externalidades de capital externo direto' que seriam capturadas por empresas nacionais de média intensidade tecnológica e esse parece ser o caso de alguns resultados encontrados neste estudo, tais como de fabricação de bebidas no PIM; o desempenho do setor minero-metálico no Pará, que possui forte participação de capital internacional/empresas multinacionais e em menor monta da agroindústria localizada nos estados do Pará, Amazonas e Tocantins, que, também, abrigam grandes players internacionais do setor de grãos, por exemplo.

Ademais, o redirecionamento do PNDR, que privilegiou o uso dos Fundos Regionais de Desenvolvimento da Região Norte para o financiamento de setores relacionados à agropecuária e à agroindústria de alimentos e bebidas, pode também ter contribuído para os movimentos aglomerativos dessas atividades no período analisado. 


\section{Considerações finais}

Em meio às transformações ocorridas na indústria brasileira, as quais têm fortalecido setores baseados em recursos naturais, buscou-se examinar como esse processo tem afetado o desempenho e a configuração espacial de 26 atividades industriais (2 dígitos CNAE 2.0) que compõem a estrutura produtiva no Norte do Brasil. Para tanto, coeficientes de aglomeração e coaglomeração usualmente empregados na literatura sobre geografia econômica e localização industrial (Krugman, 1991; Ellison e Glaeser, 1997; Ellison et al., 2007), acompanhados de indicadores de produtividade do trabalho, foram examinados no período de 2007 a 2017.

Em linhas gerais, há indícios de que atividades geograficamente mais concentradas obtiveram melhores resultados aferidos pela produtividade industrial do trabalho. Contudo, a forte heterogeneidade estaria comprometendo o desempenho produtivo, mesmo entre setores, que em tese ocupam padrões tecnológicos semelhantes.

Um exemplo disso é o alto desempenho dos Fabricantes de bebidas, se comparado aos padrões da Indústria tradicional. Neste setor, embora tenha contribuído de modo relevante para o VTI regional (12,8\% em 2007), as aglomerações resultantes dessa atividade foram restringidas pela forte concentração vertical. A produção concentrada em poucas plantas, instaladas no PIM, foi responsável por incrementar marginalmente algumas coaglomerações do G2, grupo que em média não cresceu entre 2007-2017. Assim, a assimetria identificada estaria comprometendo a competitividade setorial, bem como restringido as conexões intersetoriais.

Em contraste, entre os Fabricantes de produtos alimentícios, a organização industrial é mais competitiva. Como mostram os resultados, as coaglomerações do G4 foram as que mais cresceram (12,1\%, a.a.) entre 2007-2017, beneficiando indústrias de diferentes padrões tecnológicos, instaladas em diversas áreas na Região Norte. Ressalta-se que microrregiões especializadas em atividades agroindustriais, como encontradas em Rondônia, Pará e Tocantins, foram as mais beneficiadas com a expansão produtiva.

Cenário diferente é observado nas taxas de aglomeração (-2,33\% a.a.) e coaglomeração (-3,71\% a.a.) dos Fabricantes de produtos de madeira, que estão declinando moderadamente. Ainda que a deterioração não tenha afetado, de modo relevante, a produtividade setorial, efeitos deletérios mais evidentes são observados nas conexões intersetoriais, principalmente entre as atividades correlatas, como a Fabricação de móveis e Impressão e reprodução de gravações.

Geração e transmissão de energia elétrica é o principal segmento do padrão Energia, químicos e combustíveis no Norte. Dezenas de empreendimentos realizados em áreas estratégicas fizeram com que a produção setorial crescesse rapidamente: a participação no VTI regional passou de 7,0\% para 10,2\%, entre 2007-2017; e a região passou de $11 \%$ a contribuir com 16,1\% da geração total, no período. Apesar disso, não 
há evidência suficiente para atestar que esse setor tenha capacidade para sustentar aglomerações de qualquer natureza. Ainda que se trate de um insumo indispensável à produção industrial, postula-se que o baixo custo de transporte na transmissão estaria neutralizando o efeito proximidade espacial.

Por fim, os setores geograficamente mais concentrados no Norte são os Fabricantes de produtos de informática, eletrônicos e ópticos e Extração de minerais metálicos. $\mathrm{O}$ primeiro revela-se fortemente integrado a ramos de Bens de capital e bens duráveis no PIM. Analisando sua evolução, o padrão de crescimento próximo à média $(3,41 \%$ a.a) condiz com um quadro modesto de estabilidade observado nas conexões intersetoriais, que expandiram a uma taxa de 1,5\% a.a. Em contraste, a expansão produtiva (8,43\% a.a) dirigida pela Extração de minerais metálicos fortaleceu as conexões com seus principais fornecedores - Equipamentos de transporte, Fabricantes de produtos de madeira e Produtos alimentícios. Em consequência, as coaglomerações puxadas por essa atividade cresceram em $6,6 \%$ ao ano, em média.

\section{Referências}

Alves, P. F., Gomes, N. L., e Cavalcante, E. J. (2014). Impacto do investimento em máquinas e equipamentos sobre a inovação tecnológica ea produtividade das firmas industriais brasileiras. Texto para Discussão. Instituto de Pesquisa Econômica Aplicada (Ipea).

Andersson, M. e Lööf, H. (2011). Agglomeration and productivity: evidence from firmlevel data. The Annals of Regional Science, 46(3):601-620.

Azzoni, C. R. (1986). Indústria e reversão da polarização no brasil. Instituto de Pesquisas Econômicas, São Paulo. Tese (Livre Docência em Economia). Universidade de São Paulo.

Carvalho, P. G. M. e Feijó, C. A. (2000). Produtividade industrial no Brasil: o debate recente. Indicadores Econômicos FEE, 28(3):232-255.

Cavalcante, L. R. e De Negri, F. (2011). Trajetória recente dos indicadores de inovação no brasil.

Coelho, V. L. P. (2017). A PNDR e a nova fronteira do desenvolvimento regional brasileiro. Instituo de Pesquisa Econômica Aplicada (Ipea).

Combes, J.-L. e Guillaumont, P. (2002). Commodity price volatility, vulnerability and development. Development Policy Review, 20(1):25-39.

Combes, P.-P., Mayer, T., e Thisse, J.-F. (2008). Economic geography: The integration of regions and nations. Princeton University Press, London and New Jersey.

Crocco, M. A., Galinari, R., Santos, F., Lemos, M. B., e Simões, R. (2006). Metodologia de identificação de aglomerações produtivas locais. Nova economia, 16(2):211-241. 
De Negri, F. e Cavalcante, L. R. (2014). Os dilemas e os desafios da produtividade no brasil. In: DeNegri, F. e Cavalcante, L. R., editores, Produtividade no Brasil: desempenho e determinantes, volume 1, Capítulo 1, Página 15-52. Ipea-IBDI, Brasília.

De Negri, J. A., Salerno, M. S., e Castro, A. B. d. (2005). Inovaçoes, padrões tecnológicos e desempenho das firmas industriais brasileiras. In: Inovaçoes, Padrões Tecnológicos e Desempenho das Firmas Industriais Brasileiras, Página 05-46. Rio de janeiro: IPEA.

Diniz, C. (1993). Desenvolvimento poligonal no Brasil: nem concentração, nem contínua polarização. Nova Economia, 3(1):16-35.

Diniz, C. C. e Crocco, M. (2006). Bases teóricas e instrumentais da economia regional e urbana e sua aplicabilidade ao brasil: uma breve reflexão. In: Diniz, C. C. e Crocco, M., editores, Economia Regional e Urbana - Contribuiçoes Teóricas Recentes, volume 1, Capítulo 1, Página 9-33. Editora UFMG, Belo Horizonte.

Diniz, C. C. e Crocco, M. A. (1996). Reestruturação econômica e impacto regional: o novo mapa da indústria brasileira. Nova economia, 6(1):77-103.

Du, J. e Vanino, E. (2021). Agglomeration externalities of fast-growth firms. Regional studies, 55(2):167-181.

Dumais, G., Ellison, G., e Glaeser, E. L. (2002). Geographic concentration as a dynamic process. Review of Economics and Statistics, 84(2):193-204.

Ellery Jr, R. (2014). Desafios para o calculo da produtividade total dos fatores. In: DeNegri, F. e Cavalcante, L. R., editores, Produtividade no Brasil: desempenho e determinantes, volume 1, Capítulo 2, Página 53-86. Ipea-IBDI, Brasília.

Ellison, G. e Glaeser, E. L. (1997). Geographic concentration in US manufacturing industries: a dartboard approach. Journal of Political Economic, 1(5):889-972.

Ellison, G. e Glaeser, E. L. (1999). The geographic concentration of industry: does natural advantage explain agglomeration? American Economic Review, 21(1):311316.

Ellison, G., Glaeser, E. L., e Kerr, W. (2007). What causes industry agglomeration? evidence from coagglomeration patterns. American Economic Review, 110(3):11951213.

EPE (2018). Anuário Estatístico de Energia Elétrica 2018 - Ano base 2017. Rio de Janeiro.

Fan, C. C. e Scott, A. J. (2003). Industrial agglomeration and development: a survey of spatial economic issues in east asia and a statistical analysis of chinese regions. Economic Geography, 79(3):295-319. 
Farhauer, A. K. O. e Kröll, A. (2014). Standorttheorien-Regional-und Stadtökonomik in Theorie und Praxis. Springer, Deutschland.

Ferraz, J. C., Kupfer, D., e Haguenauer, L. (1996). Made in brazil: desafios competitivos para a indústria. Rio de janeiro: Campus, Página 386.

Florida, R., Mellander, C., Stolarick, K., e Ross, A. (2012). Cities, skills and wages. Journal of Economic Geography, 12(2):355-377.

Francois, J. e Nguyen, H. Q. (2017). Industrial clusters and firm performance. World Trade Institute Working Paper.

Gabe, T. M. e Abel, J. R. (2016). Shared knowledge and the coagglomeration of occupations. Regional Studies, 50(8):1360-1373.

Galeano, E. e Feijó, C. (2013). A estagnação da produtividade do trabalho na indústria brasileira nos anos 1996-2007: análise nacional, regional e setorial. Nova Economia, 23(1):9-50.

Galeano, E. A. V. e Wanderley, L. A. (2013). Produtividade industrial do trabalho e intensidade tecnológica nas regiões do brasil: Uma análise regional e setorial para o período 1996-2007. Planejamento e Políticas Públicas, (40):67-106.

Glaeser, E., Kallal, H., Scheinkman, J. A., e Shleifer, A. (1992). Growth in cities. Journal of Political Economy, 100(6).

Groot, S. P., de Groot, H. L., e Smit, M. J. (2014). Regional wage differences in the netherlands: Micro evidence on agglomeration externalities. Journal of Regional Science, 54(3):503-523.

Henderson, J. V. (2003). Marshall's scale economies. Journal of Urban Economics, 53(1):1-28.

Henderson, V., Kuncoro, A., e Turner, M. (1995). Industrial development in cities. Journal of Political Economy, 103(5):1067-1090.

IBGE (2014). Pesquisa industrial anual - empresa. Instituto Brasileiro de Geografia e Estatística, Rio de Janeiro, 26 edition.

Kon, A. (2017). Economia Industrial: teoria e estratégias. Alta Books Editora, Rio de Janeiro.

Koo, J. (2005). Technology spillovers, agglomeration, and regional economic development. Journal of Planning Literature, 20(2):99-115.

Krugman, P. e Venables, A. J. (1995). Globalization and the inequality of nations. The Quaterly Journal of Economics, 110(4):857-880.

Krugman, P. R. (1991). Geography and trade. Cambridge MIT Press, MassachusettsLondon. 
Lemos, M. B., Moro, S., Domingues, E. P., e Ruiz, R. M. (2005). A organização territorial da indústria no brasil. volume 1, Página 325-364. Inovaçoes, padrões tecnológicos e desempenho das firmas industriais brasileiras. Brasília: IPEA.

Maizels, A. (1988). Commodity instability and developing countries. Working Papers WP. World Institute for Development Economic Research (UNU-WIDER).

Marshall, A. (1920). Principles of economics. Macmillan, London.

Monteiro Neto, A., de Oliveira Silva, R., e Severian, D. (2021). A Indústria na Reconfiguração Territorial Brasileira: novas expressões dos dilemas nacionais no século XXI. Texto para Discussão. IPEA. Brasília.

Monteiro Neto, A. e Silva, R. d. O. (2018). Desconcentração territorial e reestruturação regressiva da indústria no brasil: padrões e ritmos. Texto para Discussão N. 2402.

Nakamura, R. e Paul, C. J. M. (2009). Measuring agglomeration. In: Handbook of Regional Growth and Development Theories. Edward Elgar Publishing.

Nallari, R. e Griffith, B. (2013). Clusters of competitiveness. World Bank Publications, Washington DC.

Pacheco, C. A. (1999). Novos padrões de localização industrial? tendências recentes dos indicadores da produção e do investimento industrial. Instituto de Pesquisa Econômica Aplicada (Ipea).

Rossi, M. C. T., dos Santos, G. F., e dos Santos, A. L. M. (2017). Empresas estrangeiras e ganhos de produtividade setoriais e regionais na indústria brasileira. Planejamento e Políticas Públicas, 48(1):134-151.

Ruiz, R. M. (2006). Políticas regionais na nova geografia econômica. In: Diniz, C. C. e Crocco, M., editores, Economia Regional e Urbana - Contribuiçoes Teóricas Recentes, volume 1, Capítulo 6, Página 143-172. Editora UFMG, Belo Horizonte.

Saboia, J. (2000). Desconcentração industrial no Brasil nos anos 90: um enfoque regional. Texto para Discussão. Instituto de Pesquisa Econômica Aplicada (Ipea).

Saboia, J. (2013). A continuidade do processo de desconcentração regional da indústria brasileira nos anos 2000. Nova Economia, 23(2):219-278.

Saboia, J., Kubrusly, L. S., e Barros, A. C. (2014). Caracterização e modificaçoes no padrão regional de aglomeração industrial no Brasil no período 2003-2011. Texto para Discussão. Instituto de Pesquisa Econômica Aplicada (Ipea).

Sampaio, D. P. (2017). Desindustrialização e desenvolvimento regional no brasil (1985-2015).

Silva, A. L. F. e Diniz, M. B. (2020). Padrões de concentração regional da indústria de transformação brasileira. Nova Economia, 30(2):407-454. 
Sobrinho, E. M. G. e Azzoni, C. R. (2016). Aglomeraçoes industriais relevantes do brasil em 2010. Revista Brasileira de Estudos Regionais e Urbanos, 9(1):1-18.

Souza, F. E. P. (2015). Por que a indústria parou? In: Barbosa, N., Marconi, N., Pinheiro, M. C., e Carvalho, L., editores, Indústria e desenvolvimento produtivo no Brasil, volume 1, Capítulo 1, Página 3-30. Elsevier-FGV, Rio de Janeiro.

Squeff, G. C. e De Negri, F. (2014). Produtividade do trabalho e mudança estrutural no brasil nos anos 2000. In: De Negri, F. e Cavalcante, L. R., editores, Produtividade no Brasil: desempenho e determinantes, volume 1, Capítulo 8, Página 249-280. IpeaIBDI, Brasília.

Tveteras, R. e Battese, G. E. (2006). Agglomeration externalities, productivity, and technical inefficiency. Journal of Regional Science, 46(4):605-625.

Veloso, F., Matos, S., e Peruchetti, P. (2021). Indicadores estaduais de produtividade do trabalho no brasil. Texto para Discusão. Fundação Getúlio Vargas (FGV). Instituo Brasileiro de Economia (IBRE).

@Ev Este artigo está licenciado com uma CC BY 4.0 license. 